\title{
Ascaris suum infections in pigs born and raised on contaminated paddocks
}

\author{
H. MEJER* and A. ROEPSTORFF \\ Danish Centre for Experimental Parasitology, Department of Veterinary Pathobiology, Royal Veterinary and \\ Agricultural University, Dyrlagevej 100, DK-1870 Frederiksberg C, Denmark
}

(Received 30 November 2005; revised 24 February and 25 March 2006; accepted 25 March 2006)

\section{SUMMAR Y}

The transmission of Ascaris suum was studied in outdoor reared pigs. From May to June 2001, 6 farrowing paddocks were naturally contaminated with $A$. suum using experimentally infected seeder pigs. Early July, 1 sow farrowed on each paddock. One piglet per litter was slaughtered every second week starting at week 3 post-partum (p.p.) for registration of liver white spots and recovery of $A$. suum from the lungs and the small intestine. The last pigs were slaughtered at week 19 p.p. Faeces was examined for parasite eggs and blood was analysed for $A$. suum-specific antibodies. Weaning took place at week 7 p.p. by removing the sow. Paddock infection levels were estimated by regular examination of soil samples and in late June and late November using parasite naïve tracer pigs. Paddock contamination was high but eggs developed slowly resulting in a low initial transmission to the experimental pigs. By week 5 p.p. transmission had increased and the numbers of infective eggs in the soil increased during the study. The results indicate a continuous uptake of infective eggs, but visceral larval migration was reduced with time, probably due to the development of a pre-hepatic barrier. Nevertheless, a rather large population of adult worms remained in the pigs throughout the study, and it may primarily have been eggs ingested in the early infection phase that gave rise to the patent infections. It is suggested that neonatal exposure may result in increased persistence and size of adult worm burden and that the higher 'life-time worm burden' may be of significant economic importance.

Key words: Ascaris suum, pigs, transmission, pre-hepatic barrier, neonatal exposure, outdoor production.

\section{INTRODUCTION}

Ascaris suum is the most common helminth in Danish organic pigs (Roepstorff et al. 1992). Its larval stages may induce economic losses due to liver condemnation, while the adult worms may reduce the growth rate of the pig (Stephenson et al. 1980; Hale et al. 1985) and feed conversion (Hale et al. 1985). The parasite is transmitted through ingestion of eggs that can develop to infectivity within 4 to 6 weeks during the summer (Roepstorff and Murrell, 1997; Mejer et al. 2000) and Ascaris may remain viable in the environment for a number of years (Müller, 1953; Krasnonos, 1978). Once ingested by the host, the eggs hatch and larvae migrate through the liver and lungs, before they establish in the small intestine and begin to produce eggs at approximately 6-7 weeks post-infection (Roepstorff et al. 1997).

Following infection, a self-cure reaction may take place, eliminating the majority of larvae from the small intestine long before they become adults (Eriksen et al. 1992b; Roepstorff et al. 1997). The mechanism of this reaction is not known but it may be the result of an acquired specific immune response

\footnotetext{
* Corresponding author. Tel: +45352827 75. Fax: +453528 27 74. E-mail:hem@kvl.dk
}

(Jungersen, 2002; Miquel et al. 2005). This may in turn be influenced by the genetic background as pigs have been shown to be predisposed to infection with A. suum (Boes et al. 1998; Coates, 2000). The adult A. suum worms are typically aggregated within the host population (Eriksen et al. $1992 a$; Roepstorff et al. 1997; Boes et al. 1998; Coates, 2000). However, the above-mentioned studies have all used weaned pigs (approx. 10 weeks of age), and work by Stankiewicz et al. (1992) indicates that neonatal exposure to $A$. suum may alter the infection dynamics by increasing susceptibility or tolerance to infection. Organic production systems with outdoor farrowing facilities provide suitable conditions for transmission of A. suum (Roepstorff and Nansen, 1994) and 10 to 12-week-old pigs have been shown to excrete high numbers of $A$. suum eggs, indicating that the pigs were exposed within a few weeks after being born (Roepstorff et al. 1992; Carstensen et al. 2002).

The aim of the present study was therefore to expand the present knowledge on the epidemiology and population dynamics of swine helminths in outdoor organic production systems by giving a qualitative and quantitative description of $A$. suum infections in pigs that were born and raised on parasite contaminated-paddocks. The epidemiology of Oesophagostomum dentatum and Trichuris suis 
infections of the same pigs was also investigated and these results are reported elsewhere (Mejer and Roepstorff, 2006).

\section{MATERIALS AND METHODS}

A detailed description of the experimental design and methods are given by Mejer and Roepstorff (2006). Therefore, paddocks, animal groups, and procedures will only be presented briefly below, except for methods relating specifically to $A$. suum. Animals were treated in accordance with the Danish Animal Experimentation Directorate.

\section{Seeder pigs and parasites}

Six individual $600 \mathrm{~m}^{2}$ farrowing paddocks with clover grass were contaminated with $A$. suum by eggexcreting seeder pigs during 3 periods of 6-7 days each from 1 May to 14 June 2001. From the age of 2 to 14 weeks, the seeder pigs had been trickle inoculated once weekly with 25 A. suum eggs/kg body weight/ day corresponding to a total dose of approximately 52500 eggs/pig. The $A$. suum eggs were isolated from worms collected at a local abattoir and embryonated in $0 \cdot 1 \mathrm{M} \mathrm{H}_{2} \mathrm{SO}_{4}$ (Oksanen et al. 1990). The experimental paddocks were irrigated on 3 occasions during the summer. Faecal samples from the seeder pigs (and all other pigs) were examined for parasite eggs using a concentration McMaster technique (Roepstorff and Nansen, 1998). Based on the individual faecal egg counts, the numbers of pigs, and the periods of egg excretion, a relative contamination index $(\mathrm{CI})$ was calculated for each of the 6 contaminated paddocks (see Mejer and Roepstorff, 2006). The CI can be used for comparison of pastures contaminated by pigs of the same size but do not in it self represent an estimate of the total egg outputs per paddock as the actual faecal volumes were not known. However, using assumed faecal outputs according to body weight (A. Chwalibog, personal communication 2004) estimates of the total number of eggs excreted by the seeder pigs were calculated (see Mejer and Roepstorff, 2006). Body weight was registered every fortnight starting at the age of 7 weeks.

\section{Sows and experimental pigs}

Nine weeks before farrowing, 6 sows from an indoor herd were nose-ringed and turned out on a prefarrowing paddock lightly contaminated with A. suum. Approximately 10 days before farrowing they were placed individually on the 6 parasite contaminated experimental paddocks. One pig from each experimental litter was slaughtered for worm recovery at weeks $3,5,7,9,11,13,15$, and 19 p.p. or until no more pigs were left. The piglets were weaned by removing the sow at week 7 p.p. Both surviving pigs and pigs to be slaughtered were weighed and blood sampled at day 3 and weeks 3, 5, 7, 9, 11, 13, 15, 17, and 19 p.p. Faecal samples were collected every second week starting at week 5 p.p. and both CI and total egg output were also estimated. Blood and faecal samples were obtained from all sows at week -9 , week -2 , day 3 , and weeks 3,5 , and 7 p.p and the CI calculated.

\section{Paddock infectivity}

Soil samples. Soil samples were collected from the experimental paddocks weeks -2 (23 June), 2 (19 July), 8 (30 August), 14 (11 Oct), and 20 p.p. (24 November) for estimation of egg content. Each paddock was divided into 2 areas: 'area around the hut' and 'the rest of the paddock'. From both areas 2 replicate soil samples were collected by walking along 2 W-routes (Roepstorff and Nansen, 1998). Five g subsamples were examined using a flotation and sieving technique (Larsen and Roepstorff, 1999). Up to a 100 eggs/sample were differentiated microscopically according to Alicata (1935) and categorized as either infective if the egg contained a slender larvae, or non-infective if the egg was non-embryonated to partially embryonated. The dry matter content of the samples was determined by drying $5 \mathrm{~g}$ soil at $105^{\circ} \mathrm{C}$ for $24 \mathrm{~h}$.

Tracer pigs. Paddock infection levels were also estimated by means of helminth naïve tracer pigs late June (tracer I) and late November (tracer II) approximately corresponding to weeks -2.5 and $-19 \cdot 5$ p.p. of the experimental pigs. Two pigs were exposed to each paddock for 4 days and then moved to clean indoor pens for 10 days, whereafter the pigs were slaughtered for recovery of intestinal A. suum. According to a previous single infection study this timetable ensures that most larvae have succeeded their migration to the small intestine while expulsion has not yet started (Roepstorff et al. 1997). Faeces and blood were sampled at turn-out and at necropsy.

\section{Blood samples}

Serum was analysed for antibodies against $A$. suum $\mathrm{L}_{3}$-larval excretory/secretory products $\left(\mathrm{L}_{3}\right.$-ESP) using an indirect ELISA as described by Jungersen et al. (1999). $\mathrm{L}_{3}$-ESP have previously been designated $\mathrm{L}_{2} \mathrm{~L}_{3}$-ESP. However, there is accumulating evidence that the infective egg contains an $\mathrm{L}_{3}$-larva (Geenen et al. 1999). All tracer and sow samples were analysed but only sera from the 9 experimental pigs that survived until week 19 p.p. were analysed.

\section{Procedures at slaughter}

The pigs were euthanized using a captive bolt pistol followed by exsanguination. The small intestine was cut open, washed in saline, and the mucus scraped 
off. Large $A$. suum were removed before the intestinal contents and the mucus mixture were processed according to the agar-gel technique described by Slotved et al. (1997), modified by incubating the agar-gels for $3 \mathrm{~h}$. For all tracer pigs and experimental pigs aged 3 to 15 weeks the entire mixture of contents and mucus was processed. For experimental pigs aged 19 weeks, a subsample of $50 \%$ was examined. The lungs of the experimental pigs were digested (at weeks 3-9 p.p.: 100\%; at weeks $11-19$ p.p.: 50\%) according to Kapel and Gamble (2000), modified by digestion for $2 \mathrm{~h}$. All samples were preserved in $70 \%$ ethanol. Intestinal worms were measured to the nearest $\mathrm{mm}$. Livers from tracer and experimental pigs were examined for superficial liver white spots which were classified as being either of the diffuse granulation-tissue type or the lymphonodular type (Ronéus, 1966).

\section{Statistical analysis}

For subsequent weeks of necropsy, liver white spots and worm burdens from lungs and intestines were analysed for differences in medians using the Mann Whitney U-test to identify when significant changes in worm population took place. Although the statistical analyses used to test for differences in medians, the descriptive results are given as arithmetic means with min-max in the tables to facilitate comparison to earlier studies. Calculations were carried out using GraphPad Prism version 3 with a $5 \%$ significance level.

\section{RESULTS}

\section{Climate, paddock vegetation and pig performance}

Temperatures were average to slightly above average, while precipitation was subnormal, except for August and September when it was above average (data not shown, Danish Meteorological Institute). Initially, the paddocks were covered with high clover grass but this was reduced prior to farrowing, especially at the area around the hut. A good re-growth ensured that a fair vegetation cover remained until well into the autumn when the experimental pigs intensified their rooting. Half the experimental litters were born 6 July and the other half 8 July. No clinical symptoms of the helminth infection were observed but there was an outbreak of Erysipelothrix rhusiopathiae and the mean body weight reached $85 \mathrm{~kg}$ at week 19 p.p. For further details see Mejer and Roepstorff (2006).

\section{Parasite egg excretion by the seeder pigs and sows}

Most seeder pigs started to excrete $A$. suum eggs between weeks 7 and 11 into the infection (i.e. weeks $-10 \cdot 5$ and $-6 \cdot 5$ p.p. of the experimental pigs, Fig. 1)

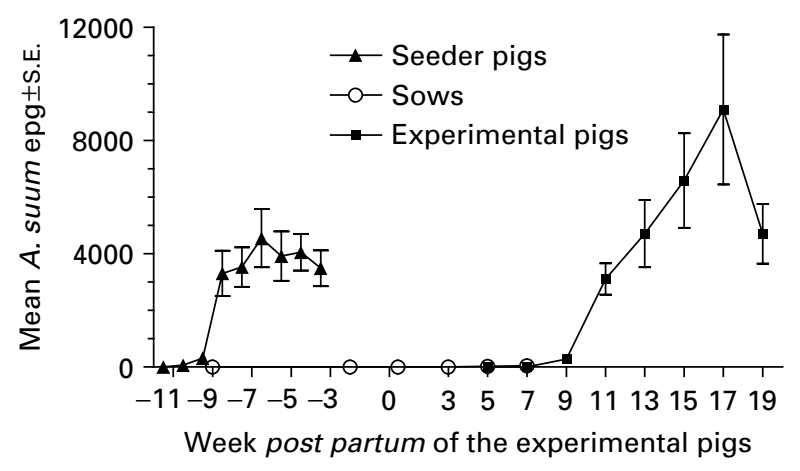

Fig. 1. Mean ( \pm s.E.) number of Ascaris suum eggs/g faeces (epg) in seeder pigs $(n=32)$, sows $(n=6)$ and their litters of experimental pigs born (week 0 ) and raised on 6 paddocks contaminated by the seeders from week $-9 \cdot 5$ to $-3 \cdot 5$. The number of experimental pigs decreased from 50 (week 5) to 9 (week 19) as pigs were slaughtered weeks $3,5,7,9,11,13,15$, and 19. At weaning week 7 the sow was removed.

and week 14 (i.e. week $-3 \cdot 5$ p.p.), $91 \%$ of the seeders had achieved patent infections. The CI varied from $5 \times 10^{5}$ to $10 \times 10^{5}$ indicating a heavy contamination of all paddocks and it was estimated that a mean of 525 million eggs/paddock were deposited by the seeder pigs. Sow faecal egg counts (Fig. 1) and thereby their contribution to the build-up of the paddock egg pool (CI: 0 to $3 \times 10^{3}$ ) was overall negligible. Antibody levels were initially high but tended to decrease slightly until the end of the suckling period when they increased considerably (Fig. 3).

\section{Paddock infectivity}

Overall, most recovered $A$. suum eggs came from the soil around the hut (Fig. 2A). The first seemingly infective eggs were detected at week 2 p.p. and the relative proportion of fully developed eggs generally increased until week 14 p.p. By week 20 p.p. fewer eggs were embryonated coinciding with a high increase in the number of recovered eggs. There was overall no $A$. suum transmission to the tracer I pigs as no $A$. suum antibodies (data not shown) or liver white spots were recorded while only 1 pig harboured 1 A. suum larva (Fig. 2B). In contrast, all tracer II pigs had sero-converted at the time of slaughter (data not shown) and the slaughter data indicate a moderate transmission level to all pigs (Fig. 2B).

\section{Parasite infections of experimental pigs}

The mean $A$. suum egg excretion pattern of the experimental pigs is shown in Fig. 1. By the end of the experiment all but 1 pig excreted eggs but it harboured 4 adult female worms at slaughter. Egg counts were overall high except on 1 paddock were all pigs had been slaughtered by week 11 p.p. The CI therefore varied from 0 to $18 \times 10^{5}$ resulting in an 
A

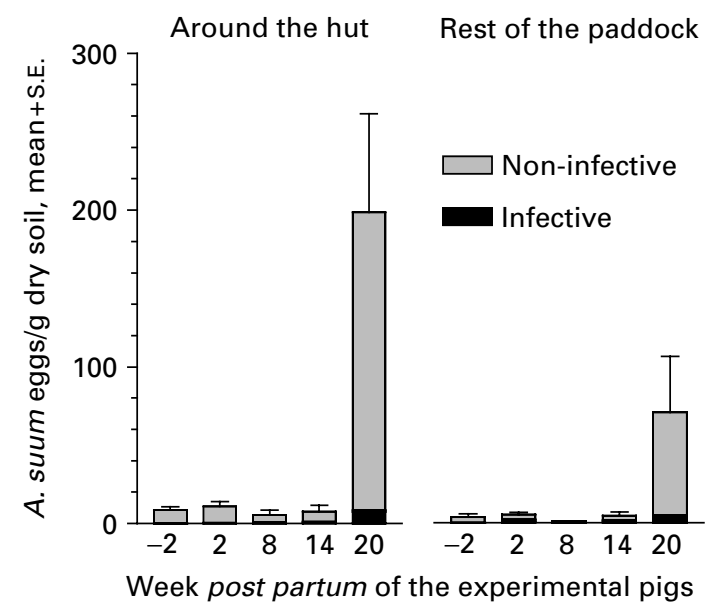

B

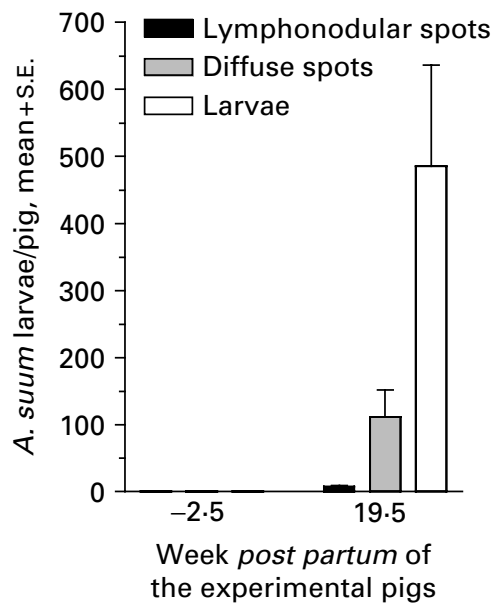

Fig. 2. Mean (+ S.E.) number of infective and non-infective Ascaris suum eggs in soil from different areas (around the hut and the rest of the paddock) of 6 paddocks (A) and liver white spots (lymphonodular and diffuse) and $A$. suum larvae in tracer pigs ( $n=2 /$ paddock) (B). The paddocks were contaminated by seeder pigs $3 \cdot 5$ to $9 \cdot 5$ weeks prior to the birth of a litter of experimental pigs on each paddock week 0 (early July 2001). Two replicate soil samples were collected from each paddock area from 23 June (week -2) to 24 November (week 20).

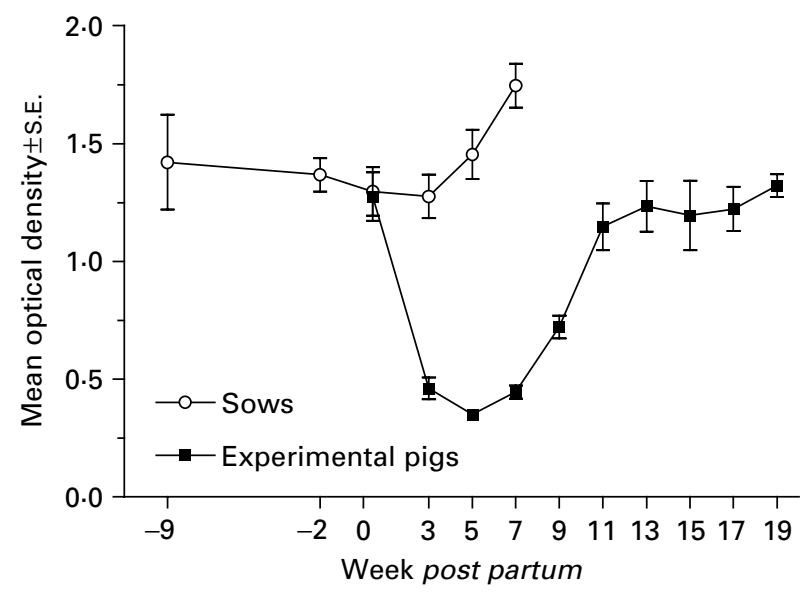

Fig. 3. Mean optical density ( \pm S.E.) as a measure of the serum level of antibodies specific for Ascaris suum $\mathrm{L}_{3}$-larvae excretory/secretory products in 9 pigs born and raised on contaminated paddocks and their sows $(n=5)$. Weaning took place at week 7 by removing the sows.

estimated high mean re-contamination of 740 million eggs/paddock.

The piglets received high levels of colostral antibodies against $\mathrm{L}_{3}$-ESP from the sows but antibody levels were reduced with time until the experimental pigs started to mount an independent acquired immune response around weaning (Fig. 3).

The necropsy results in Table 1 show that the infection pattern of the experimental pigs changed with time. The diffuse white spots increased significantly from weeks 3 to 5 p.p. $(P=0 \cdot 002)$ but then tended to decrease with time though no further significant changes took place. The lymphonodular white spots increased significantly from weeks 3 to 5 p.p. $(P=$ $0 \cdot 041)$ and again from weeks 5 to 7 p.p. $(P=0 \cdot 004)$, reflecting a longer development time compared to the diffuse white spots.

A single $A$. suum larva was recovered from the lungs of 2 pigs at week 3 p.p. (Table 1). By week 5 p.p., the numbers of lung larvae had increased significantly $(P=0.002)$ but from then on fewer larvae were detected with time. From weeks 11 to 13 p.p. $(P=0 \cdot 041)$ and weeks 13 to 15 p.p. $(P=0 \cdot 017)$ the reduction was significant. Correspondingly, the prevalence of lung larvae also decreased with time.

The first intestinal larva was found at week 3 p.p. in 1 pig (Table 1$)$. The intestinal $A$. suum were divided into 2 groups according to size ( $\leqslant 1$ or $>1 \mathrm{~cm})$. Over time the recovery of the smaller $A$. suum $(\leqslant 1 \mathrm{~cm})$ varied considerably, but after an initial significant increase between weeks 3 and 5 p.p. $(P=0.002)$ the overall trend seemed to be one of decreased infection level towards the end of the experiment, the decrease being significant between weeks 15 and 19 p.p. $(P=0 \cdot 042)$. Both at week 5 and at week 15 p.p. and to a lesser degree at week 11 p.p., 1 single pig was responsible for boosting the number of smaller $A$. suum. The larger $A$. suum $(>1 \mathrm{~cm})$ only increased significantly between weeks 5 and 7 p.p. $(P=0 \cdot 015)$ (Table 1$)$. The individual lengths of all $A$. suum recovered from the small intestine of all sacrificed pigs are shown in Fig. 4. It is noticeable that the intestinal populations seem to be separated into subpopulations of smaller and larger worms by week 9 p.p. This process continued so that there were no longer any worms of an intermediary size $(1.8$ to $6.0 \mathrm{~cm})$ by week 13 p.p. By week 19 the populations had been separated a little further as no worms between 1 and $6 \mathrm{~cm}$ were detected, although the worms $>6 \mathrm{~cm}$ still seemed to be growing in length. 
Table 1. Prevalence (Prev.) and mean numbers (min-max) of liver white spots (diffuse and lymphonodular) and Ascaris suum worms (in the lungs and the small intestines) in 6 litters of pigs born early July and raised on 6 contaminated paddocks

(The figures for intestinal worms are presented for small $(\leqslant 1 \mathrm{~cm})$ and larger $(>1 \mathrm{~cm})$ worms. The data were obtained by serial slaughter of $1 \mathrm{pig} / \mathrm{litter} /$ week ( $27 \mathrm{July}$ to 15 November), unless otherwise stated. Weaning took place at week 7 post-partum (p.p.) by removal of the sow.)

\begin{tabular}{|c|c|c|c|c|c|c|c|c|c|}
\hline \multirow[b]{3}{*}{$\begin{array}{l}\text { Week } \\
\text { p.p. }\end{array}$} & \multirow[b]{3}{*}{$n$} & \multicolumn{2}{|l|}{ White spots } & \multicolumn{2}{|c|}{ A. suum in the lungs } & \multicolumn{4}{|c|}{ A. suum in the small intestine } \\
\hline & & \multirow[b]{2}{*}{ Diffuse } & \multirow[b]{2}{*}{$\begin{array}{l}\text { Lympho- } \\
\text { nodular }\end{array}$} & \multirow[b]{2}{*}{$\begin{array}{l}\text { Worm } \\
\text { count }\end{array}$} & \multirow[b]{2}{*}{$\begin{array}{l}\text { Prev. } \\
(\%)\end{array}$} & \multicolumn{2}{|c|}{ Worms $\leqslant 1 \mathrm{~cm}$} & \multicolumn{2}{|c|}{ Worms $>1 \mathrm{~cm}$} \\
\hline & & & & & & $\begin{array}{l}\text { Worm } \\
\text { count }\end{array}$ & $\begin{array}{l}\text { Prev. } \\
(\%)\end{array}$ & $\begin{array}{l}\text { Worm } \\
\text { count }\end{array}$ & $\begin{array}{l}\text { Prev. } \\
(\%)\end{array}$ \\
\hline 3 & 6 & $1(0-4)$ & $1(0-5)$ & $<1(0-1)$ & 33 & $<1(0-1)$ & 17 & 0 & 0 \\
\hline 5 & 6 & $49(11-87)$ & $10(0-21)$ & $38(3-121)$ & 100 & $81(10-298)$ & 100 & $<1(0-4)$ & 17 \\
\hline 7 & 6 & $51(20-86)$ & $66(21-185)$ & $22(3-83)$ & 100 & $33(7-60)$ & 100 & $42(0-112)$ & 83 \\
\hline 9 & 6 & $50(9-115)$ & $42(0-77)$ & $16(0-50)$ & 83 & $39(0-90) \S$ & 80 & $35(0-133)$ & 67 \\
\hline 11 & 6 & N.D. & N.D. & $25(6-68)$ & 100 & $99(10-243)$ & 100 & $35(0-59)$ & 83 \\
\hline 13 & $6 * \dagger$ & $41(18-82)$ & $26(8-52)$ & $7(0-38)$ & 50 & $28(0-56)$ & 80 & $33(0-115)$ & 83 \\
\hline 15 & $5^{*}$ & $15(7-37)$ & $7(1-25)$ & $2(0-8)$ & 20 & $23(2-98)$ & 100 & $40(12-142)$ & 100 \\
\hline 19 & $9 * \div$ & $6(2-16)$ & $10(0-33)$ & $3(0-24)$ & 22 & $2(0-6)$ & 78 & $27(4-86)$ & 100 \\
\hline
\end{tabular}

* No pigs were left on 1 of the paddocks after week 11 p.p.

$\dagger$ Two pigs were slaughtered from 1 paddock.

$\$$ Two pigs from 4 paddocks and 1 pig from 1 paddock.

$\S$ Based on data from 5 pigs.

N.D., Not determined.

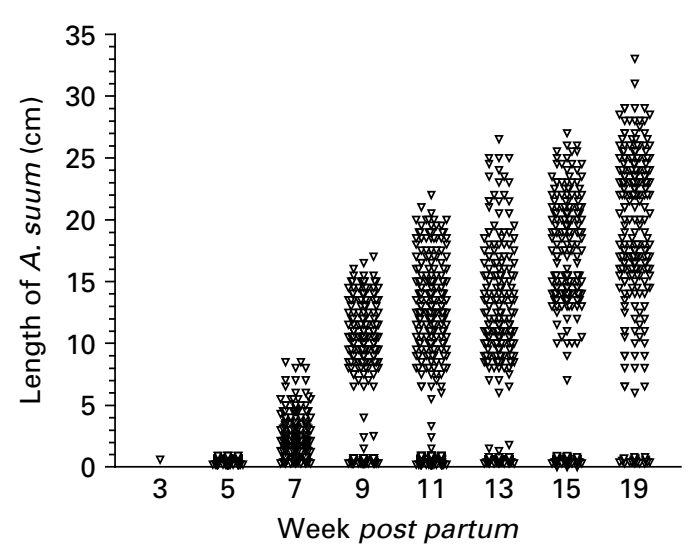

Fig. 4. Individual length of all Ascaris suum recovered from the small intestines at necropsy of a total of 50 naturally infected pigs from 6 litters born and raised on 6 contaminated paddocks. The pigs were sacrificed serially by removing $1-2$ pigs/litter at weeks $3,5,7,9,11,13,15$, and 19 post-partum or until no pigs were left.

\section{DISCUSSION}

The purpose of the experiment was to investigate the population dynamics in pigs born and raised on A. suum-infected paddocks, mimicking the situation in the outdoor pig production. Despite a very successful initial contamination by the seeder pigs at $3 \cdot 5$ to $9 \cdot 5$ weeks prior to farrowing, the majority of eggs were embryonating slowly and, as a result, the experimental pigs were not born on highly infective paddocks. The experimental data are therefore the result of a dynamic combination of gradual development of eggs, maturation of the immune system of the pigs, gradual acquisition of resistance and agerelated pig behaviour.

It has previously been shown that $A$. suum eggs may become infective to pigs within 4 to 6 weeks following excretion during a Danish summer (Roepstorff and Murrell, 1997; Mejer et al. 2000) and this has been supported by the pilot study by Larsen and Roepstorff (1999). Similarly, data from the present summer tracers and soil data show that infective eggs were present within $5 \cdot 5$ to $6 \cdot 5$ weeks after deposition. The soil data do not indicate a marked reduction in the number of eggs in the soil over the summer but a high initial mortality during at least the later part of the seeding period (Kraglund, 1999; Larsen and Roepstorff, 1999) may have reduced the number of eggs prior to the first sampling. The egg mortality was probably lower in the autumn (Kraglund, 1999; Larsen and Roepstorff, 1999) when the paddocks were heavily re-contaminated by the experimental pigs. It is unlikely that the eggs deposited by these pigs became infective within the same year as eggs deposited later than August did not embryonate until the following summer under Danish climatic conditions (Kraglund, 1999). Eggs excreted by the sows may have become infective in 2001 but, as the overall output was very low their potential contribution to paddock infection was negligible. Therefore, the increasing number of infective eggs during the summer and autumn may all originate from the seeder pigs.

Following a single infection the first $A$. suum larvae may reach the lung at day 3 p.i., though most larvae arrive a few days later (Roepstorff et al. 1997). 
Assuming this pattern does not change in the early phase of a moderate trickle infection, the lung larvae detected at week 3 p.p. may have been derived from eggs ingested 3 to 7 days before slaughter. Lymphonodular white spots may begin to appear approximately 10 days after a single infection (Roepstorff et al. 1997; Ronéus, 1966) and migrating larvae return to the small intestine around day 10 p.i. (Roepstorff et al. 1997). This suggests that the first few lymphonodular white spots as well as the first intestinal larva recorded at week 3 p.p. resulted from eggs ingested when the pigs were approximately $1 \frac{1 / 2}{2}$ weeks old and had gained access to the outdoor run. The same piglets were shown to have had ingested considerable amounts of soil by the age of 3 weeks (Mejer and Roepstorff, 2006) confirming that even very young piglets are likely to become infected if contained in a contaminated environment. Compared to the further findings of Roepstorff $e t$ al. (1997) on larval migration rates, the worm recoveries from the lungs and small intestine at week 5 p.p. indicate that a more substantial transmission to the experimental pigs took place between weeks 3 and 5 p.p. The increased transmission may be the result of an increased activity level by the piglets, as they became older and more active, combined with an increased number of infective eggs in the soil. The latter is corroborated by the elevated levels of serum antibodies in the sows at week 5 p.p., as the sows' immune system may have been boosted due to an increased ingestion of infective eggs.

It has been suggested that hyper-immunized sows may provide their offspring with a partial protection against $A$. suum infections via the colostrum (Kelley and Nayak, 1965) although no effect (Boes et al. 1999; data unpublished) and even a negative effect of sow hyper-immunization have also been recorded (Boes et al. 1999). Although our current understanding of this area is unclear, it seems unlikely that the moderate sow immune status significantly influenced infection levels in their offspring in the present study.

The decrease in numbers of liver white spots, lung larvae, intestinal larvae and worms of an intermediary size with time all lend support to the existence of a pre-hepatic barrier (Urban et al. 1988). This has been shown to develop after continuous exposure to $A$. suum and may be dose dependent. The barrier is considered to regulate the recruitment of worms to the small intestine by reducing or completely preventing the migration of newly ingested larvae from the intestine to the liver (Kelley and Nayak, 1964; Urban et al. 1988; Stankiewicz and Jeska, 1990; Eriksen et al. 1992a,b; Helwigh and Nansen, 1999; Jungersen et al. 1999). At the end of the present study the pre-hepatic barrier was not complete as a few larvae successfully migrated to the small intestine in most pigs. The absence of worms of an intermediary size does, however, suggest that the arriving larvae did not succeed in establishing in the intestine but were rapidly eliminated, corresponding to the data reported by Steenhard (2003). Both the present study and previous work (Eriksen et al. $1992 a$; Boes et al. 1998; Coates, 2000) indicate that stable populations of larger worms can persist despite an increasing resistance towards migrating larvae, this being a case of concomitant immunity as suggested by Roepstorff (2003). Overall, the inference may therefore be that the different subpopulations of newly ingested/migrating $A$. suum larvae that have just completed migration to the small intestine and larger intestinal worms are not regulated by identical immune mechanisms. Whatever the mechanisms, it seems that acquired immunity was not so important in regulating the presence of the relatively stable populations of larger intestinal A. suum within the current study period. The drop in egg excretion from weeks 17 to 19 p.p. could indicate a decreased fertility and/or the beginning of the elimination of worms. However, it may also be due to an unexplainable systematic error as the excretion of O.dentatum eggs showed a similar decrease (Mejer and Roepstorff, 2006). From an economical point of view, expulsion of large $A$. suum after week 19 , i.e. close to normal slaughter weight $(90-100 \mathrm{~kg}$ ) would probably be of little benefit as the pigs are already considered to have had a high 'life-time worm burden'. This concept is based on faecal egg counts and duration of egg excretion period of infection and has previously been associated with reduced weight gains (Bernardo et al. 1990).

It seems that establishment of large $A$. suum was more successful in both seeder pigs (trickle inoculated from 2 weeks of age) and naturally infected experimental piglets than previously described for both experimental trickle infections (Eriksen et al. $1992 a$; Coates, 2000) and natural infections in weaned young pigs (Boes et al. 1998). The reason may be that neonatal exposure to $A$. suum may either heighten susceptibility or induce tolerance to the infection in the exposed pigs (Kelley and Nayak, 1964; Stankiewicz et al. 1992; Stankiewicz and Froe, 1995), resulting in long-term persistence of relatively high numbers of adult worms. However, recent work has shown that very high natural exposure may result in expulsion of intestinal $A$. suum before 7 weeks p.p., indicating a dose-dependent response to trickle infections even in piglets (Roepstorff, unpublished). Dose dependence may explain why Jolie et al. (1998) did not detect larger intestinal worms in 7 to 10 -week-old piglets raised on contaminated pastures despite - or perhaps because of - a high transmission rate. High single doses have also resulted in poorer establishment of intestinal worms in piglets than low doses (Andersen et al. 1973; Jørgensen et al. 1975). Ascaris suum is typically highly aggregated within the host population so that the minority of the pigs harbour the majority of the worms (Eriksen et al. 1992b; Roepstorff et al. 1997; Boes et al. 1999; Coates, 
2000). Overall, it seems that the present burdens of at least the large and small $A$. suum in the intestine may have been less aggregated than reported for pigs naturally infected for 10-11 weeks (Boes et al. 1998) and pigs experimentally trickle inoculated for 10, 12, or 20 weeks (Boes et al. 1998; Coates, 2000). This may further support the hypothesis that neonatal exposure may alter the dynamics of $A$. suum infections so that relatively more animals have more comparable worm burdens.

The present data show that $A$. suum is a potential problem in organic production systems with outdoor farrowing facilities if proper control practises are not implemented. Strategic pasture rotation schemes are extremely important in the control of $A$. suum as substantial transmission to pigs and severe recontamination of paddocks can take place within the year of deposition. Unfortunately, Ascaris eggs may survive in the soil for a considerable number of years (Müller, 1953; Krasnonos, 1978) and Danish farmers often only have a limited availability of clean pastures. The long-term survival and infectivity of the A. suum eggs is therefore monitored in an ongoing study of the 6 paddocks.

J. Olesen, F. Andersen, M. Høg, M. Pearman, N. Hansen, S. Abrahamsen, K. Henriksen and the students at the Danish Centre for Experimental Parasitology are acknowledged for their skillful help. The project was funded by The Danish Research Centre for Organic Farming and The Danish National Research Foundation.

\section{REFERENCES}

Alicata, J. E. (1935). Early developmental stages of nematodes occurring in swine. US Department of Agriculture Technical Bulletin 489, 1-96.

Andersen, S., Jørgensen, R. J., Nansen, P. and Nielsen, K. (1973). Experimental Ascaris suum infections in piglets. Acta Pathologica et Microbiologica Scandinavica B 81, 650-656.

Bernardo, T. M., Dohoo, I. R. and Donald, A. (1990). Effect of ascariasis and respiratory diseases on growth rates in swine. Canadian Fournal of Veterinary Research 54, 278-284.

Boes, J., Coates, S., Medley, G. F., Varady, M., Eriksen, L., Roepstorff, A. and Nansen, P. (1999). Exposure of sows to Ascaris suum influences worm burden distributions in experimentally infected suckling piglets. Parasitology 119, 509-520.

Boes, J., Medley, G. F., Eriksen, L., Roepstorff, A. and Nansen, P. (1998). Distribution of Ascaris suum in experimentally and naturally infected pigs and comparison with Ascaris lumbricoides infections in humans. Parasitology 117, 589-596.

Carstensen, L., Vaarst, M. and Roepstorff, A. (2002). Helminth infections in Danish organic swine herds. Veterinary Parasitology 106, 253-264.

Coates, S. (2000). Modelling the population dynamics of Ascaris suum in pigs. Ph.D. thesis, Danish Centre for Experimental Parasitology, Copenhagen, Denmark and the University of Warwick, Coventry, UK.
Eriksen, L., Lind, P., Nansen, P., Roepstorff, A. and Urban, J. (1992a). Resistance to Ascaris suum in parasite naïve and naturally exposed growers, finishers and sows. Veterinary Parasitology 41, 137-149.

Eriksen, L., Nansen, P., Roepstorff, A., Lind, P. and Nilsson, O. (1992b). Response to repeated inoculations with Ascaris suum eggs in pigs during the fattening period. I. Studies on worm population kinetics. Parasitology Research 78, 241-246.

Geenen, P. L., Bresciani, J., Boes, J., Pedersen, A., Eriksen, L., Fagerholm, H.-P. and Nansen, P. (1999). The morphogenesis of Ascaris suum to the infective third-stage larvae within the egg. Fournal of Parasitology 85, 616-622.

Hale, O. M., Stewart, T. B. and Marti, O. G. (1985). Influence of an experimental infection of Ascaris suum on performance of pigs. Fournal of Animal Science 60, 220-225.

Helwigh, A. B. and Nansen, P. (1999). Establishment of Ascaris suum in the pig: development of immunity following a single primary infection. Acta Veterinaria Scandinavica 40, 121-132.

Jolie, R., Bäckström, L., Pinckney, R. and Olson, L. (1998). Ascarid infection and respiratory health in feeder pigs raised on pasture or in confinement. Swine Health and Production 6, 115-120.

Jungersen, G., Eriksen, L., Roepstorff, A., Lind, P., Meeusen, E. N. T., Rasmussen, T. and Nansen, $P$. (1999). Experimental Ascaris suum infection in the pig: protective memory response after three immunizations and effect of intestinal adult worm population.

Parasite Immunology 21, 619-630.

Jungersen, G. (2002). Immunity and immune responses to Ascaris suum in pigs. In The Geohelminths: Ascaris, Trichuris and Hookworm (ed. Holland, C. V. and Kennedy, M. W.), pp. 105-124. Kluwer Academic Publishers. Boston, Dordrecht, London.

Jørgensen, R. J., Nansen, P., Nielsen, K., Eriksen, L. and Andersen, S. (1975). Experimental Ascaris suum infection in the pig. Population kinetics following low and high levels of primary infection in piglets. Veterinary Parasitology 1, 151-157.

Kape1, C. M. O. and Gamble, H. R. (2000). Infectivity, persistence, and antibody response to domestic and sylvatic Trichinella spp. in experimentally infected pigs. International Fournal for Parasitology 30, 215-221.

Kelley, G. W. and Nayak, D. P. (1964). Acquired immunity to migrating larvae of Ascaris suum induced in pigs by repeated oral inoculations of infective eggs. Fournal of Parasitology 50, 499-503.

Kelley, G. W. and Nayak, D. P. (1965). Passive immunity to Ascaris suum transferred in colostrum from sows to their offspring. American Fournal of Veterinary Research 26, 948-950.

Kraglund, H.-O. (1999). Survival, development and dispersal of the free-living stages of Ascaris suum, Oesophagostomum dentatum and Trichuris suis at the pasture. Ph.D. thesis, the Royal Veterinary and Agricultural University, Copenhagen, Denmark.

Krasnonos, L. N. (1978). Prolonged survival of Ascaris lumbricoides L., 1758 ova in the soil in Samarkand. Meditsinskaya Parazitologicya i Parazitarnye Bolezni 47, 103-105. 
Larsen, M. N. and Roepstorff, A. (1999). Seasonal variation in development and survival of Ascaris suum and Trichuris suis eggs on pastures. Parasitology 119, 209-220.

Mejer, H. and Roepstorff, A. (2006). Oesophagostomum dentatum and Trichuris suis infections in pigs born and raised on contaminated paddocks. Parasitology 133, This issue.

Mejer, H., Wendt, S., Thomsen, L. E., Roepstorff, A. and Hindsbo, O. (2000). Nose-rings and transmission of helminth parasites in outdoor pigs. Acta Veterinaria Scandinavica 41, 153-165.

Miquel, N., Roepstorff, A., Bailey, M. and Eriksen, L. (2005). Host immune reactions and worm kinetics during the expulsion of Ascaris suum in pigs. Parasite Immunology 27, 79-88.

Müller, G. (1953). Untersuchungen über die Lebendsdauer von Askarideneiern in Gartenerde. Zentrallblatt für Bakteriologie, Parasitenkunde, Infektionskrankheiten und Hygiene 159, 377-379.

Oksanen, A., Eriksen, L., Roepstorff, A., Ilsøe, B., Nansen, P. and Lind, P. (1990). Embryonation and infectivity of Ascaris suum eggs. A comparison of eggs collected from worm uteri with eggs isolated from pig faeces. Acta Veterinaria Scandinavica 31, 393-398.

Roepstorff, A. (2003). Ascaris suum in pigs: population biology and epidemiology. Doctorate thesis, the Royal Veterinary and Agricultural University, Copenhagen, Denmark.

Roepstorff, A., Eriksen, L., Slotved, H.-C. and Nansen, P. (1997). Experimental Ascaris suum infection in the pig: worm population kinetics following single inoculations with three doses of eggs. Parasitology 115, 443-452.

Roepstorff, A., Jørgensen, R. J., Nansen, P., Henriksen, S. Aa., Skovgaard Pedersen, J. and Andreasen, M. (1992). Parasitter hos økologiske svin (Parasites in organic swine). Project report, financed by the Danish Ministry of Agriculture. Landsudvalget for svin, Danske slagterier, Copenhagen.

Roepstorff, A. and Murrell, K. D. (1997). Transmission dynamics of helminth parasites of pigs on continuous pasture: Ascaris suum and Trichuris suis. International Fournal for Parasitology 27, 563-572.
Roepstorff, A. and Nansen, P. (1994). Epidemiology and control of helminth infections in pigs under intensive and non-intensive production systems. Veterinary Parasitology 54, 69-85.

Roepstorff, A. and Nansen, P. (1998). The Epidemiology, Diagnosis and Control of Helminth Parasites of Swine. A FAO Handbook. FAO, Rome, Italy.

Ronéus, O. (1966). Studies on the aetiology and pathogenesis of white spots in the liver of pigs. Acta Veterinaria Scandinavica 7(Suppl.16), 1-112.

Slotved, H.-C., Barnes, E. H., Eriksen, L., Roepstorff, A., Nansen, P. and Bjørn, H. (1997). Use of an agar-gel technique for large-scale application to recover Ascaris suum larvae from intestinal contents of pigs. Acta Veterinaria Scandinavica 38, 207-212.

Stankiewicz, M. and Froe, D. L. (1995). Unabbreviated Ascaris suum immunizing infections of piglets lead to immunosuppression and increased numbers of intestinal parasites. Acta Parasitologica 40,152-155.

Stankiewicz, M. and Jeska, E. L. (1990). Evaluation of pyrantel-tartrate abbreviated Ascaris suum infections for the development of resistance in young pigs against migrating larvae. International Fournal for Parasitology 20, 77-81.

Stankiewicz, M., Jonas, W. and Froe, D. L. (1992). Patent infections of Ascaris suum in pigs: effect of previous exposure to multiple, high doses of eggs and various treatment regimens. International Fournal for Parasitology 22, 597-601.

Steenhard, N. R. (2003). Concurrent infection with intestinal worms and bacteria in man and domestic animals - epidemiological studies in children in Guinea-Bissau and experimental model studies in pigs. Ph.D. thesis, the Royal Veterinary and Agricultural University, Copenhagen, Denmark.

Stephenson, L. S., Pond, W. G., Nesheim, M. C., Krook, L. P. and Crompton, D. W. T. (1980). Ascaris suum: nutrient absorption, growth and intestinal pathology in young pigs experimentally infected with 15-day-old larvae. Experimental Parasitology 49, $15-25$.

Urban, J. F., Alizadeh, H. and Romanowski, R. D. (1988). Ascaris suum: development of intestinal immunity to infective second-stage larvae in swine. Experimental Parasitology 66, 66-77. 